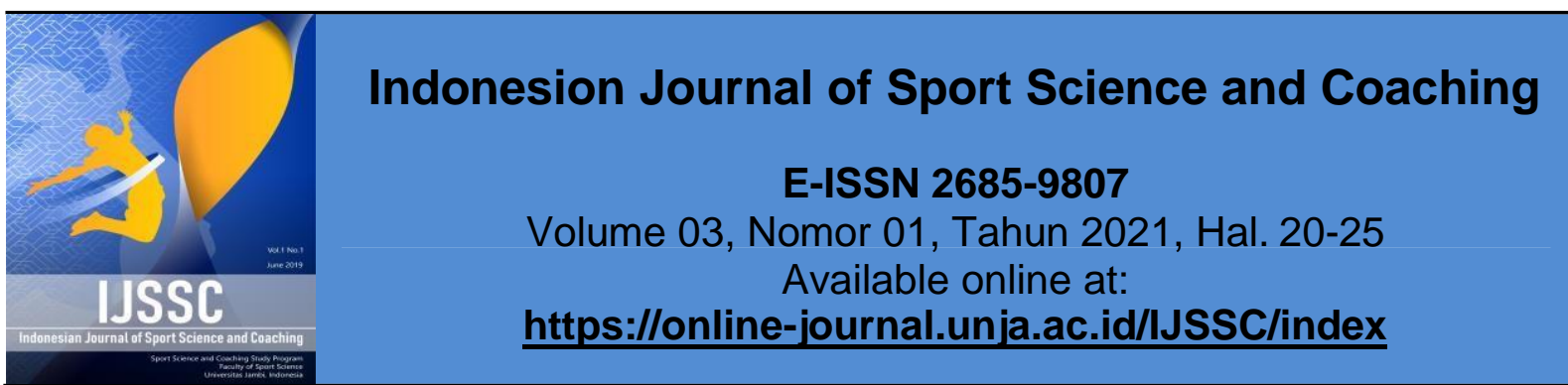

Research Article

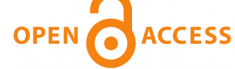

\title{
Upaya Pengenalan Olahraga Bridge Melalui Video Tutorial di Kabupaten Tanjung Jabung Barat
}

\section{(Efforts to Introduce Bridge Sports Through Video Tutorial in Tanjung Jabung Barat Regency)}

Sri Hartini
Magister Teknologi Pendidikan, Universitas Jambi
Correspondence Author : Srih6040@gmail.com


melalui berbagai akun media social seperti Youtube. Video tutorial di upload pada akun yuotube, yang kemudian disebarkan melalui facebook dan whatsaap. Video tutorial yang peneliti unggah di Youtube, Facebook, dan WhatsApp selama 12 hari mendapatkan 57 komentar, 122 like, 73 subscriber, dan telah di tonton sebanyak 310 kali. Yang mana keseluruhan tanggapan tersebut merupakan tanggapan yang positif. Sedangkan dari hasil pengisian angket oleh 35 responden, didapatkan persentase skor sebesar 74,01 \% dengan kriteria baik. Berdasarkan data tersebut dapat disimpulkan bahwa upaya pengenalan olahraga Bridge di Kabupaten Tanjung Jabung Barat efektif dilakukan melalui video tutorial. .

Kata Kunci : Pengenalan, Olahraga Bridge, Video Tutorial

This Indonesian Journal of Sport Science and Coaching is licensed under a CC BY-NC-SA (Creative Commons Attribution-ShareAlike 4.0 International License)

\section{PENDAHULUAN}

Olahraga merupakan sesuatu yang penting dalam kehidupan, karena olahraga memegang peranan penting untuk sekarang maupun yang akan datang dan merupakan salah satu kebutuhan hidup yang harus dipenuhi. Menurut Sukardjo dalam Sukadiyanto (2011), olahraga mempunyai peranan penting terutama dalam meningkatkan derajat kesehatan terutama kesehatan dinamis. Kesehatan dapat terjaga dengan mengkondisikan organ tubuh melalui olahraga. Dalam kehidupan modern saat ini manusia tidak bisa dipisahkan dari kegiatan olahraga baik sebagai kebutuhan hidup ataupun sebagai gaya hidup guna menjaga tubuh agar tetap bugar dan sehat maupun sebagai arena adu prestasi.

Undang-Undang No. 3 tahun 2005, tentang Sistem Keolahragaan Nasional, Olahraga prestasi adalah olahraga yang membina dan mengembangkan olahragawan secara terencana, berjenjang, dan berkelanjutan melalui kompetisi untuk mencapai prestasi dengan dukungan ilmu pengetahuan dan teknologi keolahragaan. Olahraga prestasi dapat dilakukan dengan persiapan yang matang agar tercapai akhir yang memuaskan. Hal ini terlihat banyaknya yang mengemari olahraga bridge yang dapat dimainkan oleh berbagai kalangan, dari berbagai lapisan masyarakat baik anak-anak, remaja dan juga orang tua. Tujuan dari olahraga bridge itu sendiri bagi sebagian orang antara lain untuk kesehatan, rekreasi dan untuk prestasi.

Peningkatanan prestasi atlit Indonesia diatur berdasarkan UU No. 3 Tahun 2005 tentang Sistem Keolahragaan Nasional (SKN). SKN merupakan salah satu kebijakan pemerintah dalam bidang olahraga. Kebijakan adalah serangkaian tindakan pemerintah untuk memanfaatkan potensi sekaligus mengatasi ancaman dalam rangka mencapai tujuan (Nugroho, 2014), dan segala sesuatu yang dilakukan atau tidak dilakukan pemerintah (Syafii, 2007). Artinya, kebijakan adalah keputusan yang menyangkut pilihan pemerintah untuk mengatur kehidupan dan tujuan bersama, termasuk keputusan pemerintah dalam mengatur olahraga nasional.

Secara definisi sistem keolahragaan adalah serangkaian aspek keolahragaan yang berkaitan, sistematis, dan berkelanjutan. Dimana terdapat pembinaan, pendidikan, dan pelatihan dalam rangka mencapai tujuan nasional dalam keolahragaan nasional. Teknis pelaksanaan berbagai kegiatan sistem keolahragaan nasional dilakukan oleh pemerintah daerah dan pusat (Permatasari, Alam, \& Nas, 2011). Dengan kata lain bahwa pemerinah berperan penting dalam menentukan keberlanjutan eksistensi dan prestasi olahraga nasional. Pada dasarnya peningkatan atlit nasional melalui pembangunan keolahragaan merupakan upaya perbaikan atau peningkatan sumberdaya manusia baik secara kualitas maupun kuantitas. Kuantitas 
melalui penambahan dan terjaminnya keberlanjutan atau regenerasi atlet nasional. Sedangkan kualitas seperti pembentukan kepribadian disiplin, beretos kerja tinggi, dan ambisi. Dua komponen tersebut, yakni kualitas dan kuantitas sebagai faktor penentu yang akan berdampak pada peningkatan prestasi atlit nasional (Hadjarati, 2009).

Berbicara mengenai olahraga berprestasi, cabang Bridge adalah cabang olahraga yang dapat membuat harum nama bangsa Indonesia di dunia. Di Indonesia sendiri cabang olahraga Bridge merupakan olahraga yang banyak diminati oleh banyak kalangan dari berbagai macam usia, dari yang kecil bahkan sampai yang tua sekalipun. Sampai dengan saat ini, perkembangan olahraga Bridge sudah menyebar ke seluruh Indonesia, terutama di Pulau Jawa.

Bridge adalah permainan kartu yang mengasah kemampuan otak kita yang memainkannya. Sebenarnya sama seperti catur yang mengandalkan kemampuan otak, bedanya bridge dimainkan secara berpasangan. Menurut perkiraan, orang yang rutin bermain bridge di Indonesia tidak lebih dari 6000 orang. Komunitas bridge nya sendiri mencapai 100.000. Dibandingkan dengan penduduk Indonesia yang mencapai 300 juta jiwa, jumlah itu amatlah kecil. Akan tetapi untuk prestasi, Atlet Bridge Indonesia sangat disegani oleh mata dunia, Indonesia selalu tampil pada Olimpiade Bridge dunia mewakili zona Asia Pasifik dan pernah menjadi juara dunia, selain itu tim Bridge Indonesia juga sering mengikuti kejuaraan-kejuaraan Internasional, dan pernah pula menjadi tuan rumah kejuaraan Internasional, seperti kejuaraan Internasional Djarum cup di Semarang.

Oahraga bridge merupakan cabang olahraga yang belum begitu dikenal di Kabupaten Tanjung Jabung Barat khususnya di Kabupaten Tanjung Jabung Barat Minat masyarakat terhadap olahraga ini masih tergolong minim. Walaupun olahraga ini secara nasional sudah mampu mendulang prestasi di dunia internasional, namun di Kabupaten Tanjung Jabung Barat khususnya di Kabupaten Tanjung Jabung Barat olahraga ini kurang berkembang. Perkembangan olahraga bridge di Kabupaten Tanjung Jabung Barat juga masih belum didukung dengan sarana dan prasarana yang memadai yang bisa mengantarkan olahraga ini supaya bisa berprestasi. Selain itu, dalam pantauan peneliti, masih belum banyak even-even yang diadakan baik untuk memperkenalkan olahraga bridge ini kepada masyarakat ataupun even-even yang diadakan untuk meningkatkan kemampuan atlet-atlet bridge di Kabupaten Tanjung Jabung Barat.

Perkembangan olahraga bridge di Kabupaten Tanjung Jabung Barat masih sangat rendah sehingga penulis akan mengenalkan olahraga bridge dengan menggunakan video tutorial secara bertahap dari Mini bridge ke permainan bridge yang sesungguhnya untuk mencapai prestasi pada even-even tingkat daerah maupun tingkat nasional sehingga atlet-atlet bridge Kabupaten Tanjung Jabung Barat bisa berprestasi dalam even-even tingkat nasional tersebut. Hal ini tentunya patut menjadi perhatian bagi pemerintah untuk mengadakan berbagai upaya supaya bisa mendorong perkembangan olahraga bridge di Kabupaten Tanjung Jabung Barat.

\section{METODE PENELITIAN}

Metode yang digunakan dalam penelitian ini adalah penelitian deskriptif kualitatif. Penelitian ini dilakukan di kabupaten Tanjung Jabung Barat. Penelitian dilakukan pada semester genap Tahun Akademik 2019/2020 yang dimulai pada bulan Februari tahun 2020.

Subjek penelitian yang dipilih adalah Pengurus cabang kabupaten Tanjung Jabung Barat, Siswa SMAN 2 Tanjung Jabung Barat, dan masyarakat Tanjung Jabung Barat. 
Pengumpulan data dilakukan dengan 2 cara, yaitu angket dan dokumentasi. Angket digunakan untuk mengetahui respon atau tanggapan masyarakat tentang olahraga Bridge. Angket respon atau tanggapan masyarakat digunakan untuk mengetahui tanggapan masyarakat tentang olahraga bridge melalui video tutorial. Dokumentasi berkaitan dengan pelaksanaan kegiatan event perlombaan olahraga bridge.

Jawaban angket respon siswa, guru, dan masyarakat umum dianalisis dengan menggunakan modifikasi skala likert 4 (empat) skala. Menurut Hadi (1991:19), modifikasi terhadap skala likert dimaksudkan untuk menghilangkan kelemahan yang terkandung oleh skala lima tingkat.

Persentase rata-rata tiap komponen dihitung dengan menggunakan rumus sebagai berikut:

$$
P=\frac{\sum x 100 \%}{N}
$$

Keterangan :

$\mathrm{P}=$ Persentase skor (dibulatkan)

$\Sigma=$ Jumlah skor yang diberikan tiap responden

$\mathrm{N}=$ Jumlah skor ideal dalam satu item.

Dengan Ketentuan:

1) Apabila hasil analisis memperoleh kriteria Sangat Baik (86\% - 100\%), maka pengenalan olahraga bridge melalui video tutorial sangat efektif.

2) Apabila hasil analisis memperoleh kriteria Baik (61\% - 80\%), maka pengenalan olahraga bridge melalui video tutorial efektif.

3) Apabila hasil analisis memperoleh kriteria Cukup Baik (41\%-60\%), maka pengenalan olahraga bridge melalui video tutorial cukup efektif.

4) Apabila hasil analisis memperoleh kriteria Kurang Baik (21\% -40\%), maka pengenalan olahraga bridge melalui video turorial kurang efektif.

5) Apabila hasil analisis memperoleh kriteria sangat kurang baik (<20\%), maka pengenalan olahraga bridge sangat tidak efektif.

\section{HASIL PENELITIAN DAN PEMBAHASAN}

Video tutorial permainan Bridge di unggah pada akun Youtube pada tanggal 16 Juni 2020 dengan alamat https://youtu.be/VYPerKIFHXA.

Tabel 1 Jumlah komentar, like dan subscribe

\begin{tabular}{cccccc}
\hline No & Akun & Komentar & Like & Subscribe & Ditonton Sebanyak \\
\hline 1 & Youtube & 43 & 83 & 73 & 310 kali \\
\hline 2 & Facebook & 14 & 39 & & \\
\hline 3 & Whatsapp & & & & 310 \\
\hline & JUMLAH & 57 & 122 & 73 & \\
\hline
\end{tabular}

Berikut merupakan hasil persentase rata-rata tiap komponen:

$$
\begin{aligned}
& \mathrm{P}=\frac{\sum \times 100 \%}{N} \\
& \mathrm{P}=\frac{2.383}{3.220} \times 100 \% \\
& \mathrm{P}=74,01 \%
\end{aligned}
$$

Olahraga Bridge adalah olahraga dengan media kartu yang membutuhkan teknik dan trik tertentu. Tidak semua orang mengerti dan memahami apa dan bagaimana teknik permainan Bridge. Karena itulah diperlukan suatu media yang baik dan tepat untuk mengenalkannya. Media yang digunakan dalam penelitian ini adalah 
video tutorial yang di unggah ke akun youtube dan di sebarluaskan melalui media sosial whatsapp, facebook dan instagram.

Video tutorial permainan Bridge ini peneliti unggah pada akun Youtube pada tanggal 16 Juni 2020. Hingga 27 Juni 2020 video tutorial tersebut telah di tonton sebanyak 310 kali. Dengan demikian dapat dikatakan bahwa masyarakat telah banyak yang menetahui olahraga Bridge. Hanya dalam waktu 10 hari saja telah di tonton sebanyak 310 kali, apalagi jika hal tersebut dilakukan secara continue, tentunya masyarakat akan lebih mengenal olahraga ini, dengan harapan mampu menarik minat masyarakat terhadap olahraga Bridge. Tingginya minat masyarakat diharapkan akan mempermudah dalam mencari bibit-bibit atlet Bridge yang baru, karena selama ini sulitnya regenerasi atlet bridge di pengaruhi oleh persepsi masyarakat yang menganggap olahraga bridge sama dengan judi.

Selain itu video tutorial yang peneliti unggah di Youtube juga mendapatkan 122 like dan 73 Subscriber (data terlampir) yang terdiri dari 83 like pada akun youtube dan 39 like pada akun facebook. Itu artinya pelan-pelan masyarakat mulai menyukai olahraga bridge. Dan berharap mendapatkan pemberitahuan apabila ada informasi terbaru tentang olahraga bridge. Ini berarti bahwa usaha pengenalan olahraga bridge melalui video tutorial dapat terus dilakukan secara continue.

Persepsi positif masyarakat terhadap olahraga bridge juga dapat diketahui melalui komentar-komentar yang diberikan oleh masyarakat pada video tutorial yang di sebarkan melalui youtube. Dari 57 komentar pada akun youtube dan facebook, semua memberikan komentar dan harapan yang positif terhadap olahraga bridge. Dengan demikian olahraga bridge mulai mendapatkan tempat di hati masyarakat, sehingga kedepannya olahraga Bridge di Kabupaten Tanjung Jabung Barat akan lebih maju.

Dikarenakan seluruh tanggapan yang ada pada akun youtube seluruhnya positif, maka dalam penelitian ini tidak perlu dilakukan revisi, dengan kata lain, bahwa upaya pengenalan olagraga bridge dapat dilakukan melalui video tutorial.

Untuk melihat apakah video tutorial efektif dalam pengenalan olahraga bridge, maka disebarkan angket ke 35 responden. Lalu dihitung persentase rata-rata.

$P=\sum \times 100 \%$

Berdasarkan jumlah skor dari pengisian angket oleh responden diperoleh:

$N$

$P=\underline{2.383} \quad x 100 \%$

3.220

$\mathrm{P}=74,01 \%$

Dengan demikian hasil analisis tersebut berada pada kategori Baik yaitu $(61 \%$ $80 \%$ ). Dengan demikian dapat disimpulkan bahwa pengenalan olahraga bridge efektif dilakukan melalui video tutorial.

\section{SIMPULAN}

Berdasarkan hasil pembahasan di atas, maka sesuai tujuan penelitian maka dapat disimpulkan bahwa pengenalan olahraga Bridge di kabupaten Tanjung Jabung Barat disampaikan melalui video tutorial yang disebarluaskan melalui channel youtube dengan cara mengirimkan link channel youtube pada social media seperti facebook, whatsapp, dan instagram.

Upaya pengenalan olahraga bridge di Kabupaten Tanjung Jabung Barat efektif dilakukan melalui video tutorial. Mengikuti perkembangan zaman, pengenalan yang dilakukan melalui video tutorial lebih mudah dan cepat sampai kepada masyarakat daripada melalui tatap muka. 


\section{DAFTAR PUSTAKA}

Al-Firdaus, I. 2010. Buku lengkap menjadi kameramen Profesional. Yogyakarta : Buku Biru.

Arsyad, Azhar. 2007. Media Pembelajaran. Jakarta: PT. Raja Grafndo Persada

Asbi, Taufik. 2010. Belajar Bridge. Jakarta: GABSI

Bidang BMS PBGABSI. 2015. Mini Bridge. Jakarta : PB GABSI

Britz, Rudy. 1971. A Taxsonomy of Communication Media. Enducation Tecnology Publication, Engliwood. Cliffs,N.J.

Dinata,Yogi Nurcahyo. 2013. Penggunaan media pembelajaran video tutorial untuk meniningkatkan hasil belajar siswa tehnik gambar bangunan SMK N 1 Seyegan Pada Mata Pelajaran Menggambar dengan Autocad. Pendidikan Teknik Sipil dan Perencanaan Universitas Negeri Yogyakarta

Hadi, Sutrisno. 1991. Statistik dalam Basic Jilit 1. Yogyakarta;Andi Offset.

Hadjarti, H. 2009. Memberdayakan Olahraga Nasional. Jurnal Pelangi IImu,2 (5), 204-220

Indah, Deby \& Sari, Nurtia Nilam. 2018. Aplikasi Pendekatan Active Learning Terhadap Kemampuan Permainan Mini Bridge siswa kelas IV SD N 004 Rambah Samo..Jurnal Pendidikan Rokaniah Vol III No 3 ISSN 2527-6018 e-ISSN 25484141

Indrayana, B., \& Yuliawan, E. (2020). Survei Kelayakan Sarana Dan Prasarana pada 31 Cabang Olahraga Anggota Koni Kota Jambi Peserta Pekan Olahraga Provinsi Jambi Ke-23. Jurnal Prestasi, 4(2), 43-48.

Mukhtar. 2013. Metode Penelitian Deskriptif Kualitatif. Jakarta : GP Press Group.

Nazir, Moh. 2011. Metode Penelitian. Bogor: Ghalia Indonesia.

Nugroho, Riant. 2004. Public plicy. Jakarta: PT. Elex Media Kamputindo

Permatasari,W, Alam, A. S \& Nas, J. 2011. Analisis Perannan pemerintah Daerah

Dalam Peningkatan pretasi Olahraga Dikabupaten Maros. Jurnal IImu Pengetahuan,7(1),49-60.

Riyana, Cheppy. 2007. Pedoman Pengembangan Vidio Jakarta: P3AI UPI.

Soewandono, Tri. 2019. Bermain Bridge Asyik Dan Menyebangkan. Surabaya : Pustaka Media Guru

Sukmadinata, Nana Syaodih. 2007. Metode Penelitian Pendidikan. Bandung: Rosdakarya.

Yono, Topo. 2019. Fenomena Permainan Mini bridge di Babsi Jember. Biyormatika Jurnal IImiah FKIP Universitas Subang Vol.5 No 01 ISSN 2461-3961 eISSN 2580-6335

Yuliawan, E., \& Indrayana, B. (2020). Sosialisasi Pemahaman Penanganan Dan Pencegahan Sport Injury Pada Siswa SMP Muhammadiyah 1 Kota Jambi: Socialization of the Understanding of Handling and Prevention of Sport Injury to Students of SMP Muhammadiyah 1 Jambi City. Cerdas Sifa Pendidikan, 9(1), 5663 